\title{
A Study on Role of Chest Radiograph in Diagnosis of Etiology of Tachypnea in Children Less Than Five Years of Age \\ Dr. Mehebub Alam MBBS
}

The West Bengal University of Health Sciences, Kolkata India

DOI: 10.36348 /SJMPS.2019.v05i10.003 $\quad$ | Received: 05.09.2019| Accepted: $25.09 .2019 \mid$ Published: 11.10 .2019

*Corresponding author: Dr. Mehebub Alam

Abstract

Introduction: Respiratory diseases are the commonest cause of death in children under 5 year. Pneumonia is the leading killer of children worldwide. In developing countries childhood pneumonias are diagnosed using clinical parameters, usually based on presence of cough and increased respiratory rate. Although this is cheap, sensitive and maximizes the number of children identified and treated empirically, it is also nonspecific and highly dependent on the context in which it is being applied. So the simple chest radiograph has been an important investigative tool in the diagnoses of diseases, since the discovery of X-rays in late nineteenth century. Chest radiograph is frequently used in the management of acute lower respiratory infection in children and still considered to be the gold standard for diagnosing respiratory infection and pneumonia. Objectives: To study the role of chest radiographs in diagnosing the etiology of tachypnea in children less than five years of age and to correlate findings of chest radiographs with etiology of tachypnea. Materials and Methods: A case control study was conducted in the Department of Pediatric Medicine, CNMC, Kolkata on tachypneic children aged between 2 months to 59 months during October 2017 to September 2018, presenting to Pediatric OPD, CNMC (Calcutta National Medical College) with clinical features of tachypnea. Chest Radiographs were done and evaluated. Analysis was done by SPSS 20 software. Results: In this present study, Among 300 patients Brochiolitis was diagnosed in $30 \%$ cases, Pneumonia in $26 \%$ cases, Asthma in $15 \%$ cases, Bronchopneumonia in $8 \%$ cases; Pleural effusion and Pneumothorax in $4 \%$ cases each; Bronchiectasis, Foreign body impaction, Milliary Tuberculosis(TB), Space occupying lesion were diagnosed in $2 \%$ cases each. The comparisons between Chest $\mathrm{x}$-ray findings with Final diagnosis and Patient outcomes were significant ( $p$ value $<0.001$ ). Conclusions: In this study I have seen that chest X-ray can give useful information about the presence of pneumonia more commonly in patients who complain of cough and tachypnea for 3 days and more. So physicians should have to select patients who need x-rays to avoid unnecessary exposure to radiation and wastage of time and money for all patients with pneumonia

Keywords: Chest Radiograph, Tachypnea, Children less than five years of age.

Copyright @ 2019: This is an open-access article distributed under the terms of the Creative Commons Attribution license which permits unrestricted use, distribution, and reproduction in any medium for non-commercial use (NonCommercial, or CC-BY-NC) provided the original author and source are credited.

\section{INTRODUCTION}

Respiratory diseases are the commonest cause of death in children under 5 year. Pneumonia is the leading killer of children worldwide. It kills more children than any other illness i.e AIDS, malaria and measles-accounting for 29 per cent of all under-five deaths. It is estimated that more than 150 million episodes of pneumonia occur every year among children under five in developing countries, accounting for more than 95 per cent of all new cases worldwide. Between 11 million and 20 million children with pneumonia will require hospitalization and accounts more than 3 million or an estimated $29 \%$ of all deaths, among children younger than 5 year worldwide. In India under-five mortality is 49 deaths per 1,000 live births, and the plan is to decrease to 42 deaths per 1000 live births by 2015 according to Millennium Development Goals and pneumonia is leading cause of death in this age group.

In developing countries childhood pneumonias are diagnosed using clinical parameters, usually based on presence of cough and raised respiratory rate. Although this is cheap, sensitive and maximizes the number of children identified and treated empirically, it is also nonspecific and highly dependent on the context in which it is being applied. So the simple chest radiograph has been an important investigative tool in the diagnoses of diseases, since the discovery of X-rays in late nineteenth century. Chest radiograph is frequently used in the management of acute lower respiratory infection in children and still considered to 
be the gold standard for diagnosing respiratory infection and pneumonia.

The use of chest radiography in the initial assessment of acute lower respiratory infection rests on the assumptions that; (i) clinical assessment plus radiography results in a more accurate diagnosis than clinical assessment alone; (ii) this leads to changes in clinical management; and (iii) the changes benefit the patient.

The standard test for diagnosis of patients is a 2 view plain chest radiograph. To provide an objective end point WHO established standard categorization for radiological case definition of pneumonia, classified as:

1) Alveolar pneumonia: i.e. end point consolidation, which may be fluffy or part of whole lobe or entire lung often containing air bronchogram and or with plural effusion.

2) Non alveolar (i.e. other consolidation or infiltrate). The presence of other infiltrates as defined above in the absence of plural effusion as well as other non-end point (i.e. linear, interstitial, pre-bronchial thickening, multiple areas of atelectasis). When more than one radiological signs were present, the condition is designed as severe radiological pneumonia.

There are studies which show the importance of chest $\mathrm{x}$-ray findings in patients with severe pneumonia. One study reports $53.2 \%$ of patients with severe pneumonia have chest $X$ ray findings [1] and also other study shows $50 \%$ of chest X-rays were positive [2]. Other two reports were $42.4 \%$ [3] and 34\% [4]. There is some variation but not significant.

Several studies have found the pattern of radiologic features could not accurately distinguish a bacterial etiology from a viral etiology, although unilateral and or lobar infiltrates are often seen in bacterial pneumonia and some chest $\mathrm{x}$ ray findings shows diseases severity. One study shows that radiological findings such as multifocal bilateral distribution, the simultaneous involvement of at least three sites and right hilar consolidation are associated with severe CAP in otherwise healthy children, and could be considered markers of disease severity [5].

The studies regarding incidence of chest $\mathrm{x}$ ray findings of patients with severe pneumonia in Eastern India are scarce. In $\mathrm{CNMCH}$ pediatric emergency department, tachypnea is the commonest cause of admission. In order to diagnose pneumonia we are using clinical parameters according to WHO classification and also chest x-ray which is the gold standard and most commonly utilized tool for pediatricians in diagnosing pneumonia and other respiratory conditions. Patients can have chest $\mathrm{x}$ ray before admission or after stabilization of the patient as much as possible in the same day of admission and interpreted by radiology residents under supervision of senior radiologist. But there are few studies which shows role of chest $x$ ray to diagnose the etiology of tachypnea in children less than five years of age. Hence, this study evaluates the role of chest $x$ ray findings in diagnosing the etiology of. Tachypnea in children less than five years of age.

\section{AIMS AND OBJECTIVES Primary objective}

- To study the role of chest radiographs in diagnosing the etiology of tachypnea in children less than five years of age.

\section{Secondary objectives}

- To study the utility of chest radiographs in diagnosing the etiology of tachypnea in children.

- To correlate findings of chest radiographs and etiology of tachypnea.

- To study the reliability of chest radiographs in finding out the outcome in tachypneic children.

- To study the socio-economic status of the patient.

- To study the outcome of the patient.

\section{REVIEW OF LITERATURE}

Radiography has been an important tool in the investigation of chest infection since its invention in the late 19th century. Plain radiographs remain the most commonly used radiological tool [1]. Pediatric respiratory disease remains an important cause of morbidity in both developed and developing countries. Chest radiograph is frequently used in the management of acute lower respiratory infection in children and still considered to be the gold standard for diagnosing respiratory infection and pneumonia. Chest $\mathrm{x}$ ray positivity ranging from as low $34 \%$ to as high as $53.2 \%$.

Ali Salih KEM, et al. studied 156 patients aged between 2 month and 5 year, the chest X-ray finding of pneumonia were present in $83(53.2 \%)$ children with alveolar pneumonia accounting for 47 $(30.12 \%)$, and non-alveolar pneumonia for $36(23.10 \%)$ cases, while X-ray showed normal findings in $46.8 \%$. It was observed that $29(34.9 \%)$ chest X-ray showed severe radiological pneumonia. All children with severe pneumonia presented with fever $(100 \%)$, followed by shortness of breath (88.5\%), cough $(81.4 \%)$ and running nose $(78.2 \%)$, while grunting in two third of the cases [1].

Njeze et al. studied 100 children aged 016years out of these Thirty seven $(37 \%)$ of the radiographs were in agreement with clinical diagnosis of pneumonia while $63 \%$ radiographs had no evidence of pneumonia. The commonest finding was lobar consolidation [2]. 
Mehebub Alam; Saudi J Med Pharm Sci, Oct 2019; 5(10): 821-837

Mulholland et al. reported $34 \%$ patients with pneumonia had chest $x$ ray findings, in 248 children age between 1 month to $5 \mathrm{yrs}$ who are admitted with diagnosis of LRTI, but chest $\mathrm{x}$ ray was found for only 174 patients. Case fatality rate was $2.8 \%$ in LRTI and higher in chest $\mathrm{x}$ ray confirmed pneumonia which was $6.8 \%$ [3].

Salwa Ahmed Al-Najjar studied 356 children aged between 2 month to 10 year to determine the relationship between clinical and chest X-ray findings of pediatric patients. All children had signs and symptoms of respiratory infections for instance, fever (87.4\%), shortness of breath (99.5\%), cough (98\%), tachypnea $(73.5 \%)$, wheezes $(93.3 \%)$, chest retraction (80\%), crepitations $(82 \%)$ and, $42.4 \%$ of chest X-rays showed focal infiltrations. Three clinical parameters related to pneumonia diagnosed by chest X-ray these were, chest retraction with sensitivity of $80 \%$, and specificity of $88.29 \%$ ), tachypnea with sensitivity of $73.5 \%$ and specificity of $56.59 \%$ fever with sensitivity of $87.42 \%$ and specificity of $60.98 \%$ [4].

Patria et al. (Italian Journal of Paediatrics $2013,39: 56)$ prospectively studied on 335 children to assess radiographic findings in children with CAP of different severity in order to evaluate whether some parameters are associated with severe CAP .Of these children $22 \%$ were sever pneumonia patients. The most frequent radiological presentation was focally distributed parenchyma densities $(212,63.3 \%)$, whereas 123 patients $(36.7 \%)$ showed multifocal consolidations, predominantly bilaterally $(85 / 123,69.1 \%)$. Atelectasis and pleural effusions.

Were detected in respectively $30(8.9 \%)$ and 33 patients $(9.8 \%)$, and only five radiographs $(1.5 \%)$ showed interstitial changes. Parenchyma densities were more prevalent in the right than the left lung (263 vs $179)$, and consolidations were more frequent in the middle lung than in the lower and upper areas (247 vs 176 and 19). The most frequently affected locations were the right lower lobe $(75,22.4 \%)$, the right para cardiac field $(65,19.4 \%)$, the left lower lobe (63, $18.8 \%)$, and the right hilum $(61,18.2 \%)$. From the above findings multifocal bilateral distribution, the simultaneous involvement of at least three sites and right hilar consolidation are associated with severe CAP [5].

$\mathrm{KEY}$, et al. reported chest X-ray findings on 301 children who were admitted and research was done prospectively. Among them pulmonary infiltrate and consolidation were described in 161(54\%) and $119(40 \%)$ cases, respectively. Chest x-ray was normal for 140 cases. Overall, the median age was 17 months

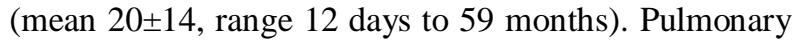
infiltrate was less frequently described among patients aged less than 1 year $(41.3 \%$ vs $59.9 \%)$ and hyperinflation was significantly more frequent in this group [6].

Grafakou et al. investigated whether chest radiographic findings could be used as predictors of severity of childhood pneumonia on 167 children, aged more than 12 months who were hospitalized with unilateral lobar or segmental pneumonia. The result was consolidation was right-sided in 109 cases and left sided in 58. The majority of children with left sided pneumonia more commonly had the lower lobe affected (lower lobe, 45/58, 77.5\%; upper lobe, 11/58, $19.1 \%$;upper and lower lobe, $2 / 58,3.4 \%$ ), while in right-sided pneumonia, the upper lobe was more commonly affected (upper lobe, 54/109, 49.5\%; lower lobe, 35/109, 32.1\%;middle lobe, 16/109, 14.7\%; and more than one lobe, 4/109, 3.6\%)and other finding was pleural effusion which was lower in patients with rightsided pneumonia $(12 / 109,11 \%)$ compared to those with left-sided $(23 / 58,39.6 \%)(\mathrm{P}<0.001)$, mainly found in lower lobe pneumonia, as it was identified in $21 / 47$ $(45 \%)$ patients with the left lower lobe affected compared to $2 / 11(18.1 \%)$ of those with pneumonia of the left upper lobe. Finally he demonstrates that right lung pneumonia is more common, with the upper lobe more frequently affected, while in left-sided pneumonia the lower lobe is preferably involved. It was also found that left-sided pneumonia was more severe compared to right sided, as indicated by the increased risk for the development of complications and delayed response to treatment [7].

Puumalainen et al. analysed 821 children $(60 \%)$ boys) who were hospitalised at the Bohol Regional Hospital. According to the WHO pneumonia severity classification algorithm, 290 episodes (24\%) were non severe pneumonia, 785 (66\%) were severe pneumonia, $120(10 \%)$ were very severe pneumonia. A blood culture was obtained in $90 \%$ of episodes. They detected 13 (1.1\% of episodes) invasive bacterial infections. The most common bacterial pathogens included Staphylococcus aureus, Streptococcus pneumoniae and Salmonella typhi. According to the retrospective review of clinical, laboratory and radiographic data, 402 episodes (33.6\%) had radiographically confirmed pneumonia as the major cause of hospitalisation. Bacteriologically confirmed bacterial pneumonia or probable bacterial pneumonia was the diagnosis in $8.6 \%, 11.5 \%$ and $15.9 \%$ of episodes in non severe, severe and very severe WHO pneumonia categories, respectively [8].

M Sheng et al. assessed the radiological presentation of 210 confirmed cases of viral pneumonia in children and reported that most common cause of viral pneumonia was influenza a infection (81 out of a total of 210 patients). Remaining 129 patients were RSV ( $\mathrm{n}=38)$, PIFV $(\mathrm{n}=28)$, adenovirus $(\mathrm{n}=27)$, influenza B $(n=18)$ and PIFV $(n=18)$. Findings in chest 
radiograph were bilateral patchy areas of consolidation in 133 patients, interstitial lung disease in 33 patients, diffuse areas of air space consolidation in 29 patients and lobar consolidation in 15 patients. Lower lobes were the most common site for abnormal radiographic abnormalities and were bilaterally involved in 195 patients and unilaterally involved in the remaining 15 cases [9].

A. G. Falade et al. evaluated 487 malnourished children aged 2 months to 5 years in developing countries and 255 well nourished children who presented with a cough or breathing difficulty. Among these radiological pneumonia was present in 145 cases (30\%) of the malnourished children and 68 cases $(26 \%)$ of well-nourished children [10].

Xavier-Souza et al. conducted a prospective study to assess the inter-observer agreement in the interpretation of several radiographic features in the chest radiographs (CXR) of 773 children aged 2-59 months with non-severe acute lower respiratory tract infection (ALRI). The overall agreement was $78.7 \%$ (normal CXR [n $=385,60.9 \%$ ], pneumonia $[\mathrm{n}=222$, $35.1 \%$, other radiological diagnosis $[\mathrm{n}=22,3.5 \%$, inappropriate for reading $[\mathrm{n}=3,0.5 \%])$. The most frequent symptoms and findings were cough (97.4\%), fever $(92.0 \%)$, rales $(64.9 \%)$, difficult breathing (62.3\%), vomiting (44.7\%) and tachypnea (44.5\%), crackles $(44.1 \%)$. The most frequent findings were atelectasis; peri bronchial thickening, hyperinflation.But abscess, pneumatocele, and pneumothorax were not described [11].

Koya Ariyoshi (Central Vietnam, April 2007March 2010) determined the incidence of radiologically-confirmed pneumonia (RCP) prospectively, among children $<5$ years of age, hospitalized with acute respiratory infection. The overall incidence of RCP for children $<5$ years of age was $3.3(2.3-3.8)$ per 1000 children, and the highest incidence, 8.3 (3.8-10.5) per 1000 children, was observed in the 12- to 23-month age group. This incidence is lower than those in the previous studies from other developing countries. A 5-6 times higher annual RCP incidence was reported in Brazil (1-35 months: $36.2 / 1000$ children) 15 and the Northern Territory Indigenous (1 month-5years; 26.6 per 1000, 111 months: 57.5/1000, 12-23 months: 38.3/1000 children).16 Studies from the Philippines and Indonesia also had reported higher annual RCP incidences of $13.5 / 1000$ and $8.9 / 1000$ per children (1.5-23months) respectively $[17,18]$. A slightly higher annual RCP incidence of 4.3/1000 children (1-59 months) also was reported in Fiji. Several factors might be responsible for the lower RCP incidence in Vietnam, which include availability of free health care for children $<6$ years of age, implementation of Integrated Management of Childhood Illnesses guidelines for treatment of pneumonia in primary health care level, widespread use of antibiotics, improving social-economic status, and better access to medical care in Vietnam [12].

M. Javadi et al. reported $166(86 \%)$ patients with pneumonia had chest $\mathrm{x}$ ray finding which was done on the 192 radiographs from patients with clinical pneumonia and found radiological abnormalities in $166(86 \%)$ patients. Seventy-eight $(47 \%)$ of the pneumonias had alveolar consolidation and $80(48 \%)$ had Interstitial pattern only and the rest have other evidence of pneumonia even though not specified [13].

Northeast Brazil, researched on 472 children, aged 6-59 months, with clinically-diagnosed pneumonia who were either admitted to or treated as out patients and he found out that confirmatory infiltrate on the chest X-ray was present in $389(86.1 \%)$ of 452 patients and in $228(92.7 \%)$ of 246 admitted to the hospital. An alveolar non-lobar infiltrate (non-perihilar) was the most common radiological finding in 221 cases (56.8\%). Lung complications were present in 56 cases (11.9\%), Pleural effusion in 34 cases $(8.7 \%)$. He also reported the causes of pneumonia i.e bacteria were identified in $26.7 \%$ of the cases, while viruses and mixed infections accounted for $8.4 \%$ and $2.7 \%$ respectively. Haemophilus influenzae (18.9\%), Streptococcus pneumonia (6.4\%), and respiratory syncytial virus $(5.0 \%)$ were most often identified [15].

\section{MATERIALS AND METHODS}

a) Study design/experiment design: This is an institution based observational study

b) Study settings \& timelines: The study will be conducted in the Department of Pediatric Medicine, CNMC, Kolkata on tachypneic children aged between 2 months to 59 months.

c) Place of study: Department of Pediatric Medicine, Calcutta National Medical College and Hospital, Kolkata

d) Period of study: Cases will be recorded over a period of one year (October 2017 to September 2018).

e) Study population: Patients aged between 2 months to 59 months presenting to Pediatric OPD, CNMC with clinical features of tachypnea.

f) Sample size/design: All patients attending the Pediatric Emergency of $\mathrm{CNMCH}$, Kolkata during the study period fulfilling the inclusion and exclusion criteria. According to the prevalence of Acute Respiratory Tract infections in children aged between 2 months to 5 years, the sample size should be 800 . This will not be feasible for me, so I am taking 300 samples.

g) Control required or not: Not required 


\section{h) Inclusion criteria}

1. Patients aged between 2 months to 59 months, presenting with clinical features of tachypnea due to respiratory causes and willing to participate in the study through a written informed consent (annexure 1).

WHO Age- Dependent Criteria for diagnosing tachypnea in children

$<2$ months ------- $>60$ breaths/min

$$
\text { 2-11 months ------ }>50 \text { breaths/min }
$$

12-59 months ------ $>40$ breaths/min

\section{i) EXCLUSION CRITERIA}

- Patients less than 2 months and more than 59 months will be excluded from the study.

- Tachypnea due to non-respiratory causes (eg.Cardiac causes, Neurological causes, metabolic causes, Traumatic causes) will be excluded from the study.

- Tachypnea due to upper respiratory tract infections will be excluded from the study.

j) Study variables: Demographics, Clinical features and chest radiograph findings of tachypnea.

k) Data collection: Patients aged between 2 months to 59 months attending Pediatric OPD suspected with clinical features of tachypnea due to respiratory cause will be included for investigation once consented to participate in the study.

\section{l) Laboratory investigations \& parameters}

- Routine Laboratory Investigations including complete blood count, liver function test, urea and creatinine, serum electrolytes, capillary blood sugar, Urine for routine examination and microscopical examination, blood culture(if needed), blood serology(if needed).

- Chest radiographs

- Ultrasonography(if needed)

- CT scan of chest(if needed)

Outcome definition and parameters and procedures

- Patients aged between 2 months to 59 months attending Pediatric OPD with tachypnea due to respiratory cause will be included in the study.

- Written informed consent will be taken from the patient.

- History and clinical examination findings will be recorded in a case record form.

- Routine laboratory investigations and appropriate special investigations will be done.

- Chest radiographs will be done for each patient.

Definition of the outcomes: Not applicable as this is an observational study. n) Additional resources: This study will be conducted by support of department of radiology, $\mathrm{CNMCH}$, Kolkata.

6) Statistical analysis plan: Data will be analyzed by appropriate statistical tests using statistical software SSPE version 20 $\left(\right.$ sample size $\left.=4 \mathrm{pq} / \mathrm{L}^{2}\right)$.

\section{STATISTICAL METHODS}

Categorical variables are expressed as Number of patients and percentage of patients and compared across the groups using Pearson's Chi Square test for Independence of Attributes/ Fisher's Exact Test as appropriate. The statistical software SPSS version 20 has been used for the analysis. An alpha level of 5\% has been taken, i.e. if any $\mathrm{p}$ value is less than 0.05 it has been considered as significant.

\section{Photographs}

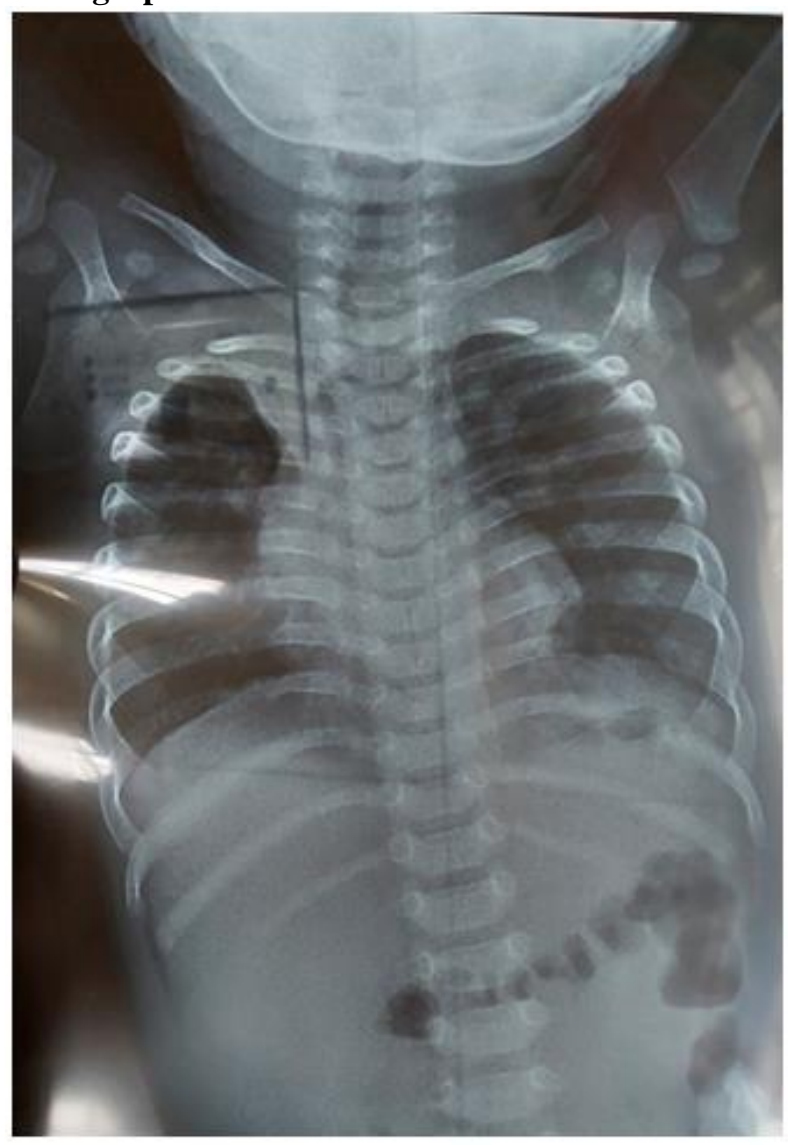

\section{CXR SHOWING PNEUMONIA \\ RESULTS AND ANALYSIS}

This study was conducted from October 2017 to September 2018. A total 960 children with signs and symptoms of respiratory tract involvement were seen at the pediatric emergency ward of Calcutta National Medical College and Hospital. Of these Chest radiographs were obtained in 300 patients, presented with tachypnea and the radiographs were subsequently reviewed by pediatric radiologist. 
Table-1: Distribution by Age

\begin{tabular}{|c|c|c|}
\hline Age & Frequency & Percent \\
\hline < 1 Year & 180 & 60.0 \\
\hline 1-2 Years & 78 & 26.0 \\
\hline 2-5 Years & 42 & 14.0 \\
\hline Total & 300 & 100.0 \\
\hline
\end{tabular}

In this present study, among 300 patients, $60 \%$ are infants, $26 \%$ are between 1-2 yrs of age and $14 \%$ are between 2-5 yrs of age.

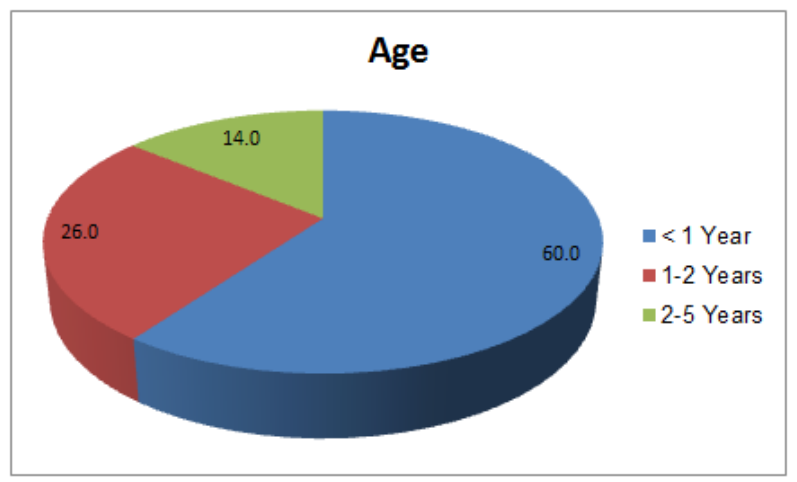

Table-2: Distribution by Sex

\begin{tabular}{|c|c|c|}
\hline Sex & Frequency & Percent \\
\hline Male & 156 & 52.0 \\
\hline Female & 144 & 48.0 \\
\hline Total & 300 & 100.0 \\
\hline
\end{tabular}

In this present study, among 300 patients, $52 \%$ are male and $48 \%$ are female.

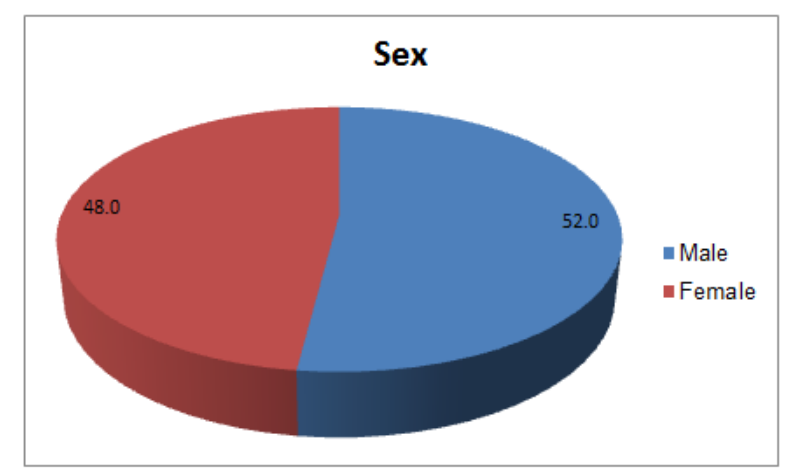

Table 3: Distribution by Socio-economic status

\begin{tabular}{|c|c|c|}
\hline SES & Frequency & Percent \\
\hline LOWER & 195 & 65.0 \\
\hline MIDDLE & 75 & 25.0 \\
\hline UPPER & 30 & 10.0 \\
\hline Total & 300 & 100.0 \\
\hline
\end{tabular}

In this present study, among 300 patients, $65 \%$ from lower, $25 \%$ from middle, $10 \%$ from upper socioeconomic classes.

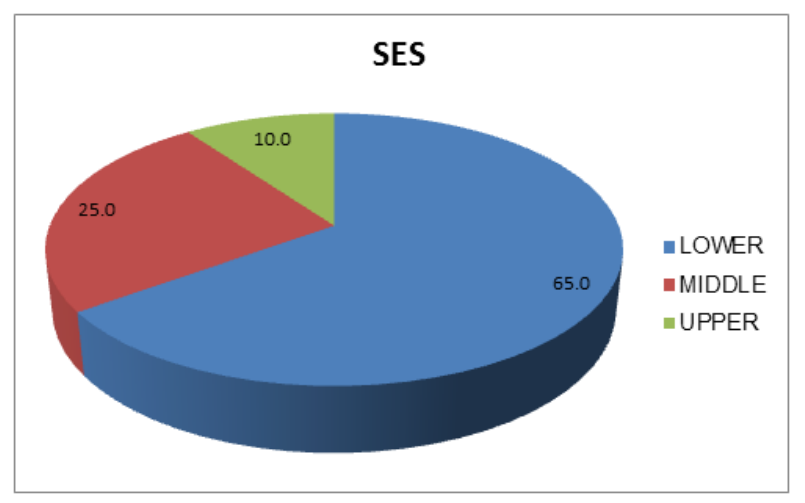

Table-4: Fever with cough as Chief complaints (CC)

\begin{tabular}{|c|c|c|}
\hline fever and Cough & Frequency & Percent \\
\hline No & 174 & 58.0 \\
\hline Yes & 126 & 42.0 \\
\hline Total & 300 & 100.0 \\
\hline
\end{tabular}

In this present study, Fever with cough was present in $42 \%$ cases.

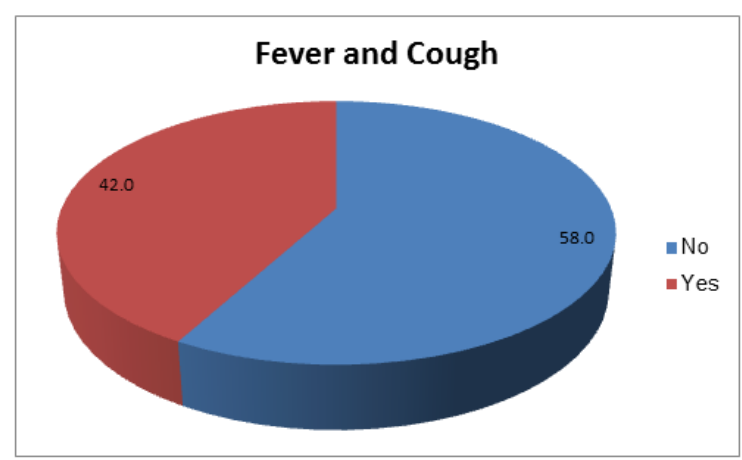

Table-5: Only Fever as Chief complaint

\begin{tabular}{|c|c|c|}
\hline fever and IRB & Frequency & Percent \\
\hline No & 273 & 91.0 \\
\hline Yes & 27 & 9.0 \\
\hline Total & 300 & 100.0 \\
\hline
\end{tabular}

In this present study, Only Fever was present in $9 \%$ cases.

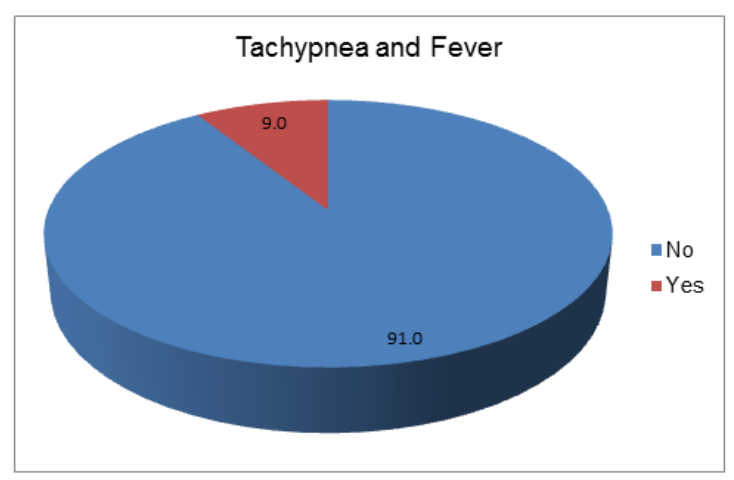


Table 6: Only Cough as Chief complaint

\begin{tabular}{|c|c|c|}
\hline IRB and Cough & Frequency & Percent \\
\hline No & 234 & 78.0 \\
\hline Yes & 66 & 22.0 \\
\hline Total & 300 & 100.0 \\
\hline
\end{tabular}

In this present study, only Cough was present in $22 \%$ cases.

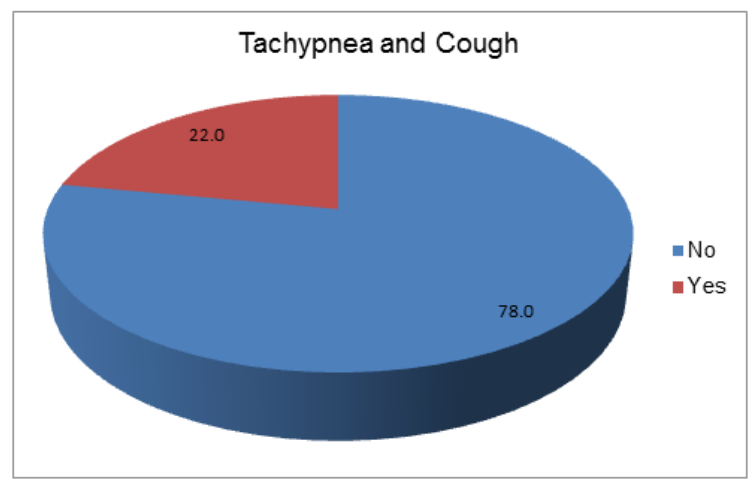

Table-7: Only Grunting as Chief complaint

\begin{tabular}{|c|c|c|}
\hline fever and grunting & Frequency & Percent \\
\hline No & 291 & 97.0 \\
\hline Yes & 9 & 3.0 \\
\hline Total & 300 & 100.0 \\
\hline
\end{tabular}

In this present study, only Grunting was present in $3 \%$ cases.

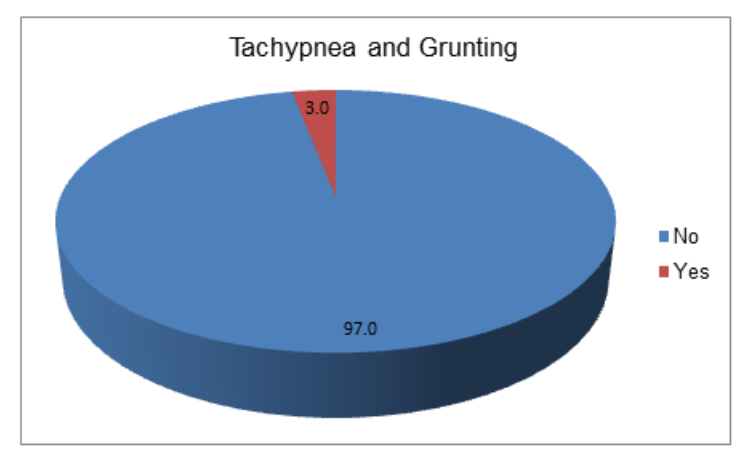

Table-8: Cough and Grunting as chief complaints

\begin{tabular}{|c|c|c|}
\hline Cough and grunting & Frequency & Percent \\
\hline No & 297 & 99.0 \\
\hline Yes & 3 & 1.0 \\
\hline Total & 300 & 100.0 \\
\hline
\end{tabular}

In this present study, Cough with grunting was present in $1 \%$ cases.

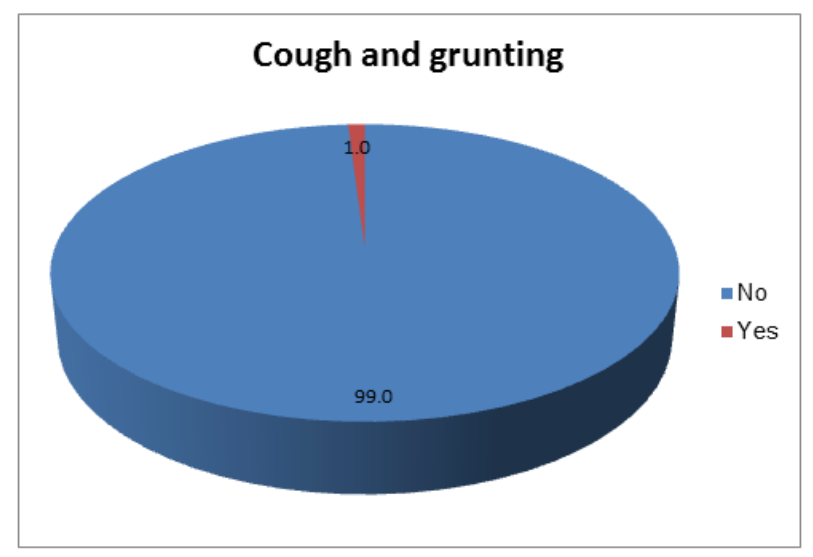

Table-9: Fever with cough and grunting as chief complaints

\begin{tabular}{|c|c|c|}
\hline $\begin{array}{c}\text { Fever and Cough and } \\
\text { grunting }\end{array}$ & Frequency & Percent \\
\hline No & 297 & 99.0 \\
\hline Yes & 3 & 1.0 \\
\hline Total & 300 & 100.0 \\
\hline
\end{tabular}

In this present study, Fever with cough and grunting was present $1 \%$ cases.

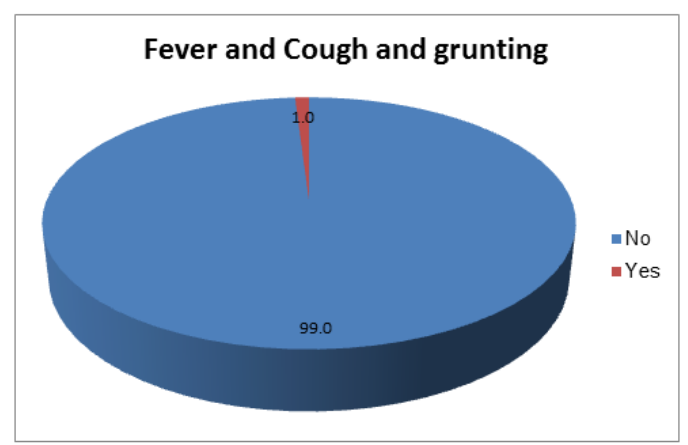

Table 10: Difficulty in Breathing (Dyspnea)

\begin{tabular}{|c|c|c|}
\hline DIB & Frequency & Percent \\
\hline No & 15 & 5.0 \\
\hline Yes & 285 & 95.0 \\
\hline Total & 300 & 100.0 \\
\hline
\end{tabular}

In this present study, Difficulty in breathing (dyspnea) was present in $95 \%$ cases.

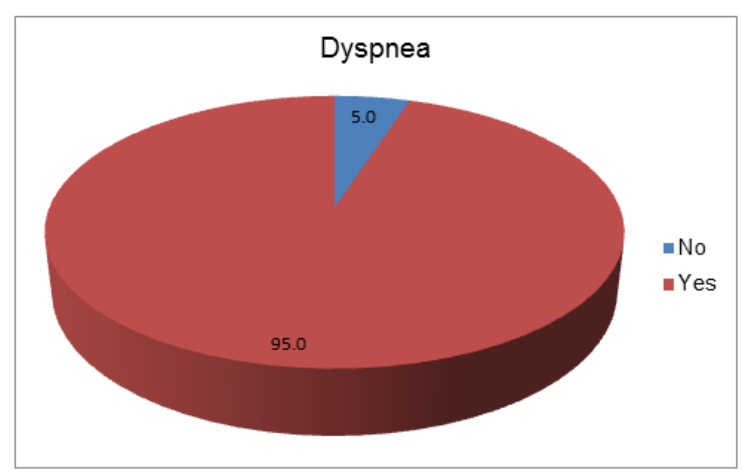


Mehebub Alam; Saudi J Med Pharm Sci, Oct 2019; 5(10): 821-837

Table 11: Distribution by Similar illness in the past \begin{tabular}{|c|c|c|}
\hline Similar History in the past & Frequency & Percent \\
\hline & &
\end{tabular}

\begin{tabular}{|c|c|c|}
\hline No & 183 & 61.0 \\
\hline Yes & 117 & 39.0 \\
\hline Total & 300 & 100.0 \\
\hline
\end{tabular}

In this present study, past history of similar illness was present in $39 \%$ cases.

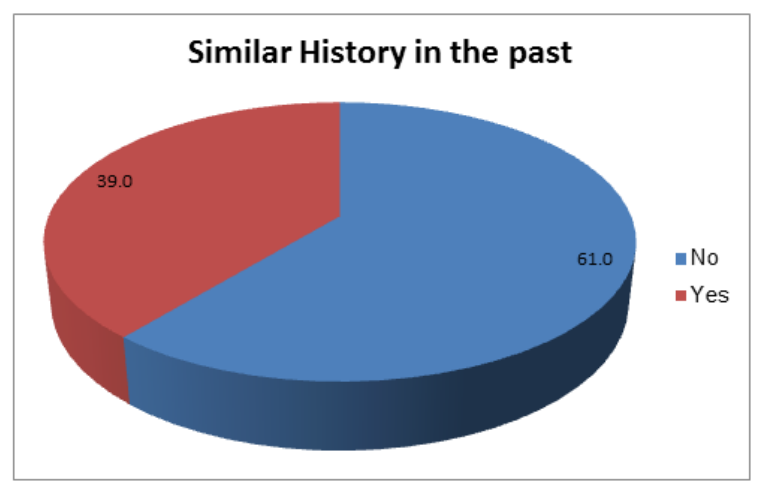

Table 12: Distribution by Frequency of past history of similar illness

\begin{tabular}{|c|c|c|}
\hline $\begin{array}{c}\text { Frequency of H/O past } \\
\text { illness }\end{array}$ & Frequency & Percent \\
\hline Once & 24 & 20.5 \\
\hline Twice & 33 & 28.2 \\
\hline 3 Times & 45 & 38.5 \\
\hline 4 Times & 15 & 12.8 \\
\hline Total & 117 & 100.0 \\
\hline \multicolumn{2}{|c}{} \\
\hline
\end{tabular}

In this present study, past history of similar illness was 3 times in $38.5 \%$ cases, twice in $28.2 \%$ cases, once in $20.5 \%$ cases, 4 times in 12.85 cases.

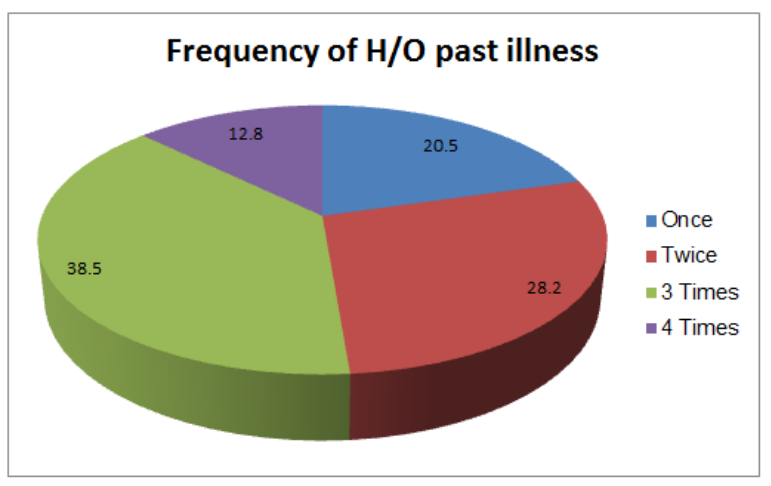

Table-13: Distribution by Auscultatory chest findings

\begin{tabular}{|c|c|c|}
\hline Auscultatory chest findings & Frequency & Percent \\
\hline wheeze(p) and crepitation & 75 & 25.0 \\
\hline no finding & 57 & 19.0 \\
\hline wheeze only & 54 & 18.0 \\
\hline crepitation only & 30 & 10.0 \\
\hline $\begin{array}{c}\text { both crepitation(p) and } \\
\text { wheeze }\end{array}$ & 27 & 9.0 \\
\hline diminished VBS & 27 & 9.0 \\
\hline BBS(p) and crepitation & 15 & 5.0 \\
\hline $\begin{array}{c}\text { BBS(p), crepitation and } \\
\text { wheeze }\end{array}$ & 9 & 3.0 \\
\hline diminished VBS, wheeze & 6 & 2.0 \\
\hline Total & 300 & 100.0 \\
\hline
\end{tabular}

In my study; Predominantly wheeze with crepitation was present in $25 \%$ cases, no finding seen in $19 \%$ cases, only wheeze $18 \%$ cases, only crepitation in $10 \%$ cases, predominantly crepitation with wheeze in 9\% cases, diminished Vesicular breath sound (VBS) in 9\% cases, Predominantly Bronchial breath sound (BBS) with crepitation and wheeze in $3 \%$ cases, diminished Vesicular breath sound with wheeze in $2 \%$ were present.

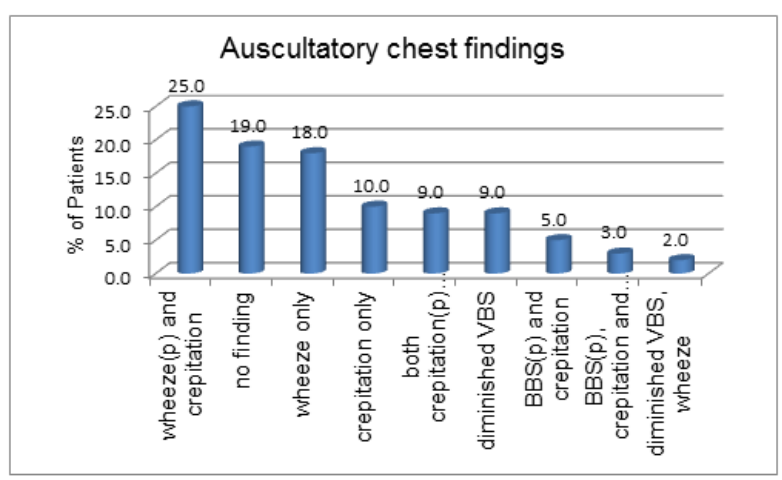

Table-14: Distribution by Site of Auscultatory chest finding

\begin{tabular}{|c|c|c|}
\hline Site of chest finding & $\begin{array}{c}\text { Frequenc } \\
\mathbf{y}\end{array}$ & Percent \\
\hline B/L & 147 & 49.0 \\
\hline Left & 33 & 11.0 \\
\hline Right & 69 & 23.0 \\
\hline No Finding & 51 & 17.0 \\
\hline Total & 300 & 100.0 \\
\hline \multicolumn{2}{|r}{}
\end{tabular}

In this present study, Auscultatory chest findings were present bilaterally in $49 \%$ cases, in right lung $23 \%$ cases, in left lung $11 \%$ cases. 


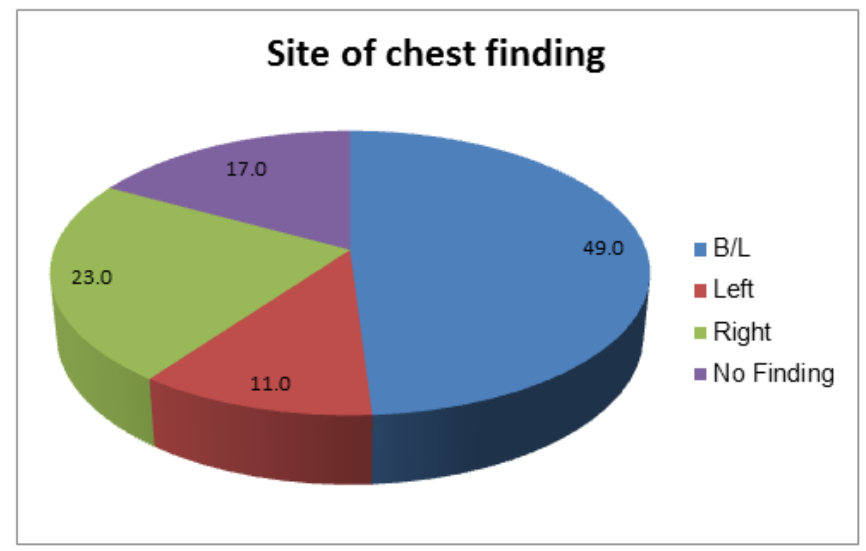

Table-15: Distribution by Chest x-ray findings

\begin{tabular}{|c|c|c|}
\hline CXR & Frequency & Percent \\
\hline Hyper Inflation with parahilar opacity and increased bronchovascular markings & 90 & 30.0 \\
\hline Consolidation & 72 & 24.0 \\
\hline Hyperinflation & 51 & 17.0 \\
\hline Bronchopneumonia & 24 & 8.0 \\
\hline Interstitial Pneumonia & 15 & 5.0 \\
\hline Pleural Effusion & 12 & 4.0 \\
\hline Hyperlucent lung field with collapsed lung border & 12 & 4.0 \\
\hline Atelectasis & 6 & 2.0 \\
\hline Unspecified & 6 & 2.0 \\
\hline Rounded homogenous opacity & 6 & 2.0 \\
\hline Honeycomb lesion & 6 & 2.0 \\
\hline Total & 300 & 100.0 \\
\hline
\end{tabular}

In Chest x-ray findings of this present study, Hyperinflation with parahilar opacity and increased bronchovascular markings was present in 30\% cases, Consolidation in $24 \%$ cases, Hyperinflation in $17 \%$ cases, Bronchopneumonia in $8 \%$ cases, Interstitial pneumonia in $5 \%$ cases, Pleural effusion in $4 \%$ cases;Atelectasis, Rounded homogenous opacity, Honeycomb lesion and Unspecified findings were seen in $2 \%$ cases each.

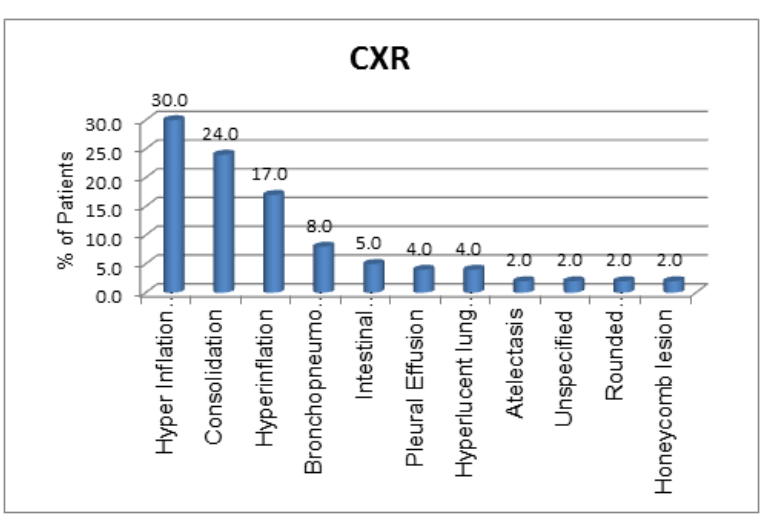

Table-16: Distribution by Lobe involvement (Chest X-ray finding)

\begin{tabular}{|c|c|c|}
\hline Lobe involvement & Frequency & Percent \\
\hline B/L & 189 & 64.3 \\
\hline Left lung & 15 & 5.1 \\
\hline LLL & 9 & 3.1 \\
\hline LUL & 9 & 3.1 \\
\hline Right lung & 9 & 3.1 \\
\hline RLL & 15 & 5.1 \\
\hline RML & 15 & 5.1 \\
\hline RUL & 33 & 11.2 \\
\hline Total & 294 & 100.0 \\
\hline \multicolumn{2}{|c}{}
\end{tabular}

In CXR findings of this present study, Bilateral lobe(B/L) involvement was seen in $64.3 \%$ cases, Right upper lobe(RUL) involved in $11.2 \%$ cases; Right middle lobe(RML), Right lower lobe(RLL) and whole left lung involved in $5.1 \%$ cases each; Left upper lobe(LUL), Left lower lobe(LUL) and whole Right lung involved in $3.1 \%$ cases each. 
Mehebub Alam; Saudi J Med Pharm Sci, Oct 2019; 5(10): 821-837

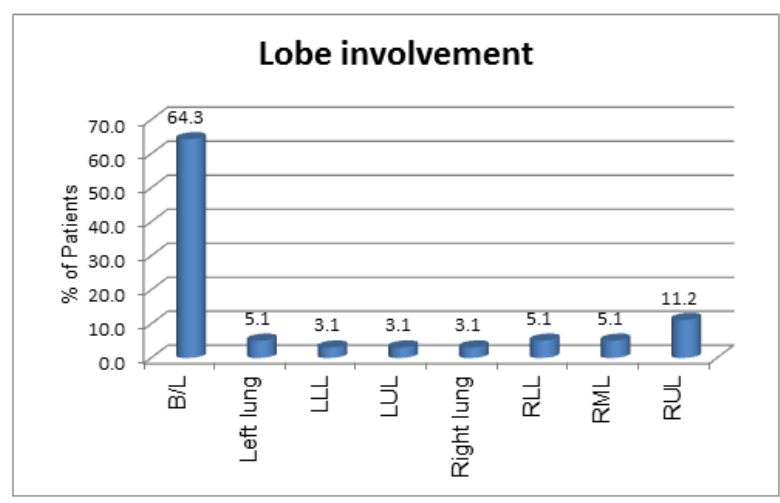

Table-17: Distribution by Final Diagnosis

\begin{tabular}{|c|c|c|}
\hline Final Diagnosis & Frequency & Percent \\
\hline Bronchiolitis & 90 & 30.0 \\
\hline Pneumonia & 78 & 26.0 \\
\hline Asthma & 45 & 15.0 \\
\hline Bronchopneumonia & 24 & 8.0 \\
\hline Interstitial pneumonia & 15 & 5.0 \\
\hline Pleural effusion & 12 & 4.0 \\
\hline Pneumothorax & 12 & 4.0 \\
\hline Bronchiectasis & 6 & 2.0 \\
\hline Foreign body impaction & 6 & 2.0 \\
\hline milliary TB & 6 & 2.0 \\
\hline Space occupying lesion & 6 & 2.0 \\
\hline Total & 300 & 100.0 \\
\hline
\end{tabular}

In this present study, Among 300 patients Brochiolitis was diagnosed in $30 \%$ cases, Pneumonia in $26 \%$ cases, Asthma in $15 \%$ cases, Bronchopneumonia in $8 \%$ cases; Pleural effusion and Pneumothorax in $4 \%$ cases each; Bronchiectasis, Foreign body impaction, Millary Tuberculosis(TB), Space occupying lesion were diagnosed in $2 \%$ cases each.

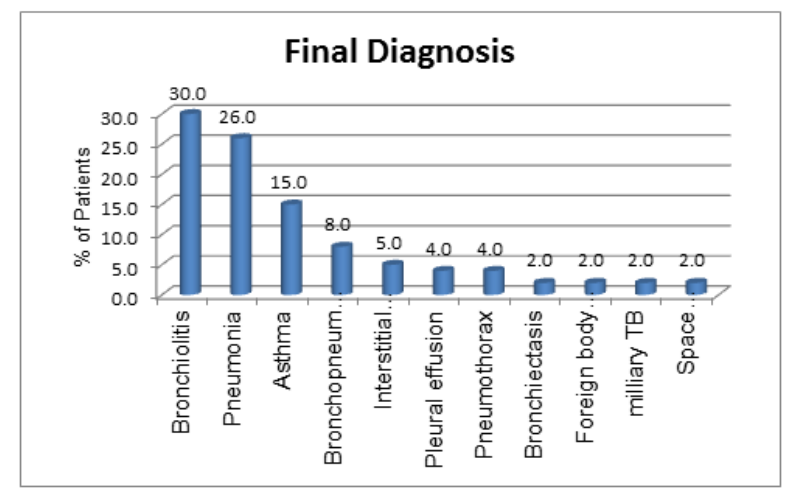

Table 18: Distribution by Duration of Hospital stay

\begin{tabular}{|c|c|c|}
\hline Duration of H/S(days) & Frequency & Percent \\
\hline$<4$ days & 60 & 20.0 \\
\hline 4 to 7 days & 150 & 50.0 \\
\hline$>7$ days & 90 & 30.0 \\
\hline Total & 300 & 100.0 \\
\hline
\end{tabular}

In this present study $50 \%$ cases stayed in hospital for 4-7 days, $30 \%$ cases for $>7$ days and $20 \%$ case $<4$ days.

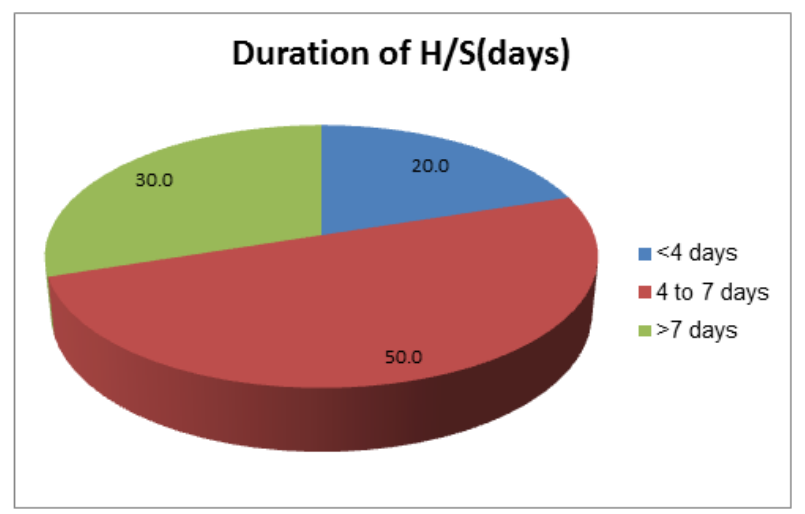

Table-19: Distribution by Outcome

\begin{tabular}{|c|c|c|}
\hline Outcome & Frequency & Percent \\
\hline Discharged & 270 & 90.0 \\
\hline Death & 30 & 10.0 \\
\hline Total & 300 & 100.0 \\
\hline
\end{tabular}

In this present study, $90 \%$ patients were discharged after clinical improvement.

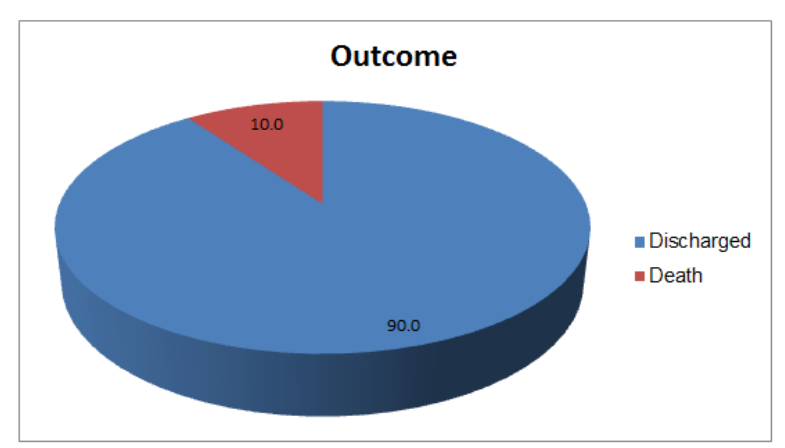


Mehebub Alam; Saudi J Med Pharm Sci, Oct 2019; 5(10): 821-837

Table-20: Compasion between CXR findings and Lobe involvement

\begin{tabular}{|c|c|c|c|c|c|c|c|c|c|c|}
\hline & \multicolumn{6}{|c|}{ Lobe involvement } & \multirow[t]{2}{*}{ Total } & & \\
\hline & & $\mathrm{B} / \mathrm{L}$ & LLL & LUL & RLL & RML & RUL & & $\mathbf{p}$ & Significance \\
\hline \multirow[t]{9}{*}{ CXR } & Consolidation & $30(15.87)$ & $6(66.67)$ & $9(100)$ & $0(0)$ & $9(60)$ & $18(54.55)$ & $72(26.67)$ & \multirow[t]{9}{*}{$<0.001$} & \multirow[t]{9}{*}{ Significant } \\
\hline & Bronchopneumonia & $12(6.35)$ & $0(0)$ & $0(0)$ & $6(40)$ & $6(40)$ & $0(0)$ & $24(8.89)$ & & \\
\hline & Interstitial Pneumonia & $6(3.17)$ & $0(0)$ & $0(0)$ & $0(0)$ & $0(0)$ & $9(27.27)$ & $15(5.56)$ & & \\
\hline & $\begin{array}{c}\text { Hyper Inflation with } \\
\text { parahilar opacity and } \\
\text { increased bronchovascular } \\
\text { markings }\end{array}$ & $90(47.62)$ & $0(0)$ & $0(0)$ & $0(0)$ & $0(0)$ & $0(0)$ & $90(33.33)$ & & \\
\hline & Atelectasis & $0(0)$ & $3(33.33)$ & $0(0)$ & $3(20)$ & $0(0)$ & $0(0)$ & $6(2.22)$ & & \\
\hline & Unspecified & $6(3.17)$ & $0(0)$ & $0(0)$ & $0(0)$ & $0(0)$ & $0(0)$ & $6(2.22)$ & & \\
\hline & Hyperinflation & $45(23.81)$ & $0(0)$ & $0(0)$ & $0(0)$ & $0(0)$ & $0(0)$ & $45(16.67)$ & & \\
\hline & $\begin{array}{c}\text { Rounded homogenous } \\
\text { opacity }\end{array}$ & $0(0)$ & $0(0)$ & $0(0)$ & $0(0)$ & $0(0)$ & $6(18.18)$ & $6(2.22)$ & & \\
\hline & Honeycomb lesion & $0(0)$ & $0(0)$ & $0(0)$ & $6(40)$ & $0(0)$ & $0(0)$ & $6(2.22)$ & & \\
\hline & Total & $189(100)$ & $9(100)$ & $9(100)$ & $15(100)$ & $15(100)$ & $33(100)$ & $270(100)$ & & \\
\hline
\end{tabular}

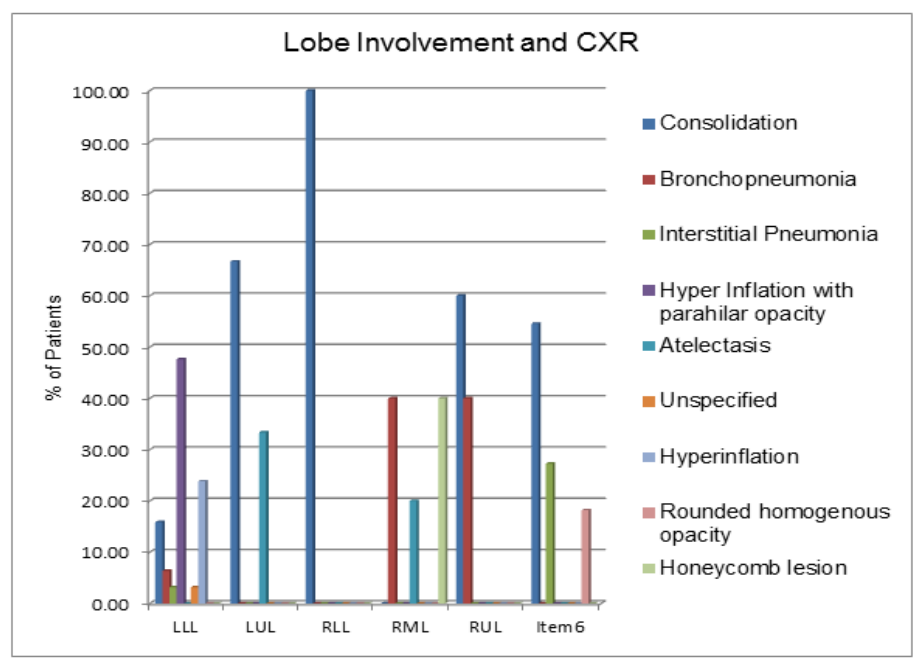

Table-21: Comparison between CXR findings and Duration of illness

\begin{tabular}{|c|c|c|c|c|c|c|c|}
\hline & \multicolumn{3}{|c|}{ Duration of illness(days) } & \multirow[b]{2}{*}{ Total } & \multirow[b]{2}{*}{$\begin{array}{c}\mathbf{p} \\
\text { Value }\end{array}$} & \multirow[b]{2}{*}{ Significance } \\
\hline & & $\begin{array}{c}\text { Within } 3 \\
\text { days }\end{array}$ & $\begin{array}{l}4 \text { to } 7 \\
\text { days }\end{array}$ & $>7$ days & & & \\
\hline \multirow{11}{*}{ CXR } & Consolidation & $45(62.5)$ & $24(33.33)$ & $3(4.17)$ & $72(100)$ & \multirow{11}{*}{$<0.001$} & \multirow{11}{*}{ Significant } \\
\hline & Bronchopneumonia & $9(37.5)$ & $15(62.5)$ & $0(0)$ & $24(100)$ & & \\
\hline & Interstitial Pneumonia & $12(80)$ & $3(20)$ & $0(0)$ & $15(100)$ & & \\
\hline & Pleural Effusion & $0(0)$ & $0(0)$ & $12(100)$ & $12(100)$ & & \\
\hline & $\begin{array}{l}\text { Hyper Inflation with parahilar opacity } \\
\text { and increased bronchovascular markings }\end{array}$ & $54(60)$ & $33(36.67)$ & $3(3.33)$ & $90(100)$ & & \\
\hline & Atelectasis & $3(50)$ & $3(50)$ & $0(0)$ & $6(100)$ & & \\
\hline & Unspecified & $3(50)$ & $3(50)$ & $0(0)$ & $6(100)$ & & \\
\hline & Hyperinflation & $15(29.41)$ & $24(47.06)$ & $12(23.53)$ & $51(100)$ & & \\
\hline & $\begin{array}{l}\text { Hyperlucent lung field with collapsed } \\
\text { lung border }\end{array}$ & $6(50)$ & $6(50)$ & $0(0)$ & $12(100)$ & & \\
\hline & Rounded homogenous opacity & $3(50)$ & $3(50)$ & $0(0)$ & $6(100)$ & & \\
\hline & Honeycomb lesion & $6(100)$ & $0(0)$ & $0(0)$ & $6(100)$ & & \\
\hline & Total & $156(52)$ & $114(38)$ & $30(10)$ & $300(100)$ & & \\
\hline
\end{tabular}




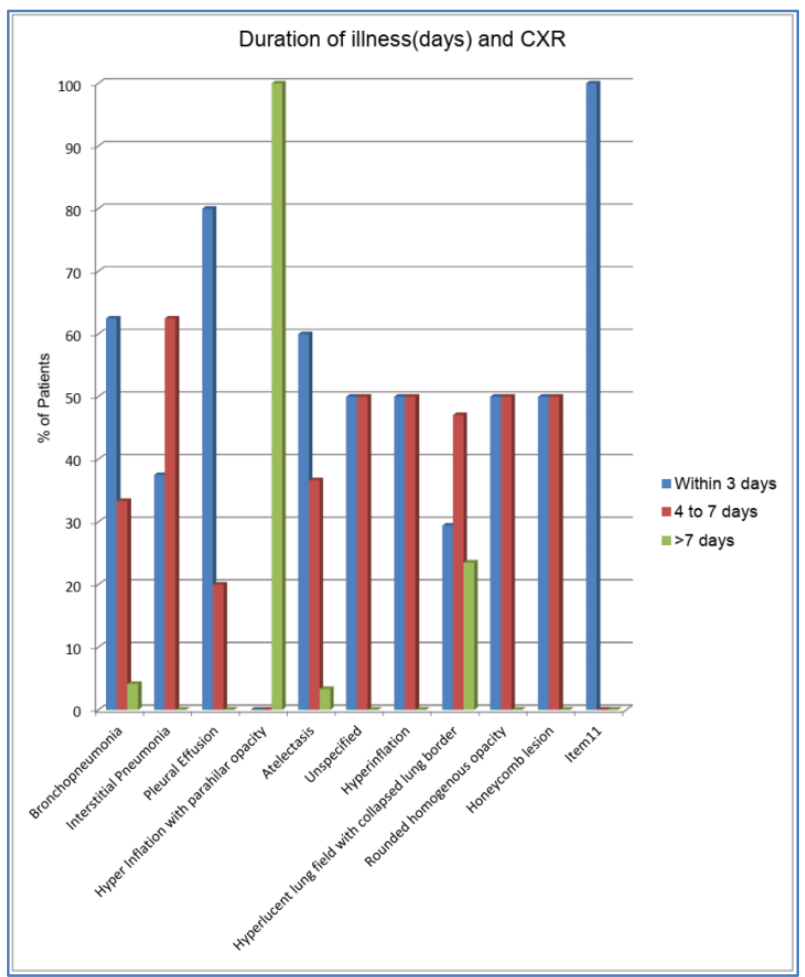

Table-22: Comparison between CXR findings and Duration of Hospital stays (H/S)

\begin{tabular}{|c|c|c|c|c|c|c|c|}
\hline & \multicolumn{3}{|c|}{ Duration of $\mathbf{H} / \mathrm{S}$ (days) } & \multirow[b]{2}{*}{ Total } & \multirow[b]{2}{*}{ p Value } & \multirow[b]{2}{*}{ Significance } \\
\hline & & $<4$ days & $\begin{array}{l}4 \text { to } 7 \\
\text { days }\end{array}$ & $>7$ days & & & \\
\hline \multirow{11}{*}{$\begin{array}{c}\mathrm{CX} \\
\mathrm{R}\end{array}$} & Consolidation & $15(20.83)$ & $39(54.17)$ & $18(25)$ & $72(100)$ & \multirow{11}{*}{$<0.001$} & \multirow{11}{*}{ Significant } \\
\hline & Bronchopneumonia & $0(0)$ & $18(75)$ & $6(25)$ & $24(100)$ & & \\
\hline & Interstitial Pneumonia & $3(20)$ & $12(80)$ & $0(0)$ & $15(100)$ & & \\
\hline & Pleural Effusion & $0(0)$ & $0(0)$ & $12(100)$ & $12(100)$ & & \\
\hline & $\begin{array}{c}\text { Hyper Inflation with parahilar opacity } \\
\text { and increased bronchovascular markings }\end{array}$ & $27(30)$ & $39(43.33)$ & $24(26.67)$ & $90(100)$ & & \\
\hline & Atelectasis & $0(0)$ & $3(50)$ & $3(50)$ & $6(100)$ & & \\
\hline & Unspecified & $0(0)$ & $3(50)$ & $3(50)$ & $6(100)$ & & \\
\hline & Hyperinflation & $12(23.53)$ & $21(41.18)$ & $18(35.29)$ & $51(100)$ & & \\
\hline & $\begin{array}{l}\text { Hyperlucent lung field with collapsed } \\
\text { lung border }\end{array}$ & $0(0)$ & $6(50)$ & $6(50)$ & $12(100)$ & & \\
\hline & Rounded homogenous opacity & $0(0)$ & $6(100)$ & $0(0)$ & $6(100)$ & & \\
\hline & Honeycomb lesion & $3(50)$ & $3(50)$ & $0(0)$ & $6(100)$ & & \\
\hline & Total & $60(20)$ & $150(50)$ & $90(30)$ & $300(100)$ & & \\
\hline
\end{tabular}

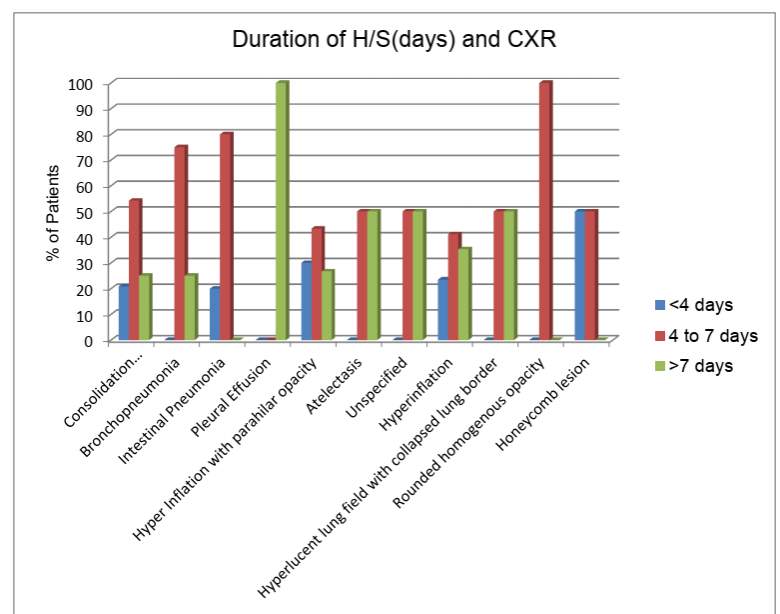


Mehebub Alam; Saudi J Med Pharm Sci, Oct 2019; 5(10): 821-837

Table-23: Comparison between CXR findings and Outcome

\begin{tabular}{|c|c|c|c|c|c|c|}
\hline & \multicolumn{2}{|c|}{ Outcome } & \multirow{2}{*}{ Total } & \multirow[b]{2}{*}{$\begin{array}{c}\mathbf{p} \\
\text { Value }\end{array}$} & \multirow[b]{2}{*}{ Significance } \\
\hline & & Discharged & Death & & & \\
\hline \multirow{11}{*}{ CXR } & Consolidation & $63(87.5)$ & $9(12.5)$ & $72(100)$ & \multirow{11}{*}{$<0.001$} & \multirow{11}{*}{ Significant } \\
\hline & Bronchopneumonia & $24(100)$ & $0(0)$ & $24(100)$ & & \\
\hline & Interstitial Pneumonia & $9(60)$ & $6(40)$ & $15(100)$ & & \\
\hline & Pleural Effusion & $9(75)$ & $3(25)$ & $12(100)$ & & \\
\hline & $\begin{array}{l}\text { Hyper Inflation with parahilar opacity and } \\
\text { increased bronchovascular markings }\end{array}$ & $81(90)$ & $9(10)$ & $90(100)$ & & \\
\hline & Atelectasis & $3(50)$ & $3(50)$ & $6(100)$ & & \\
\hline & Unspecified & $6(100)$ & $0(0)$ & $6(100)$ & & \\
\hline & Hyperinflation & $51(100)$ & $0(0)$ & $51(100)$ & & \\
\hline & $\begin{array}{l}\text { Hyperlucent lung field with collapsed lung } \\
\text { border }\end{array}$ & $12(100)$ & $0(0)$ & $12(100)$ & & \\
\hline & Rounded homogenous opacity & $6(100)$ & $0(0)$ & $6(100)$ & & \\
\hline & Honeycomb lesion & $6(100)$ & $0(0)$ & $6(100)$ & & \\
\hline & Total & $270(90)$ & $30(10)$ & $300(100)$ & & \\
\hline
\end{tabular}

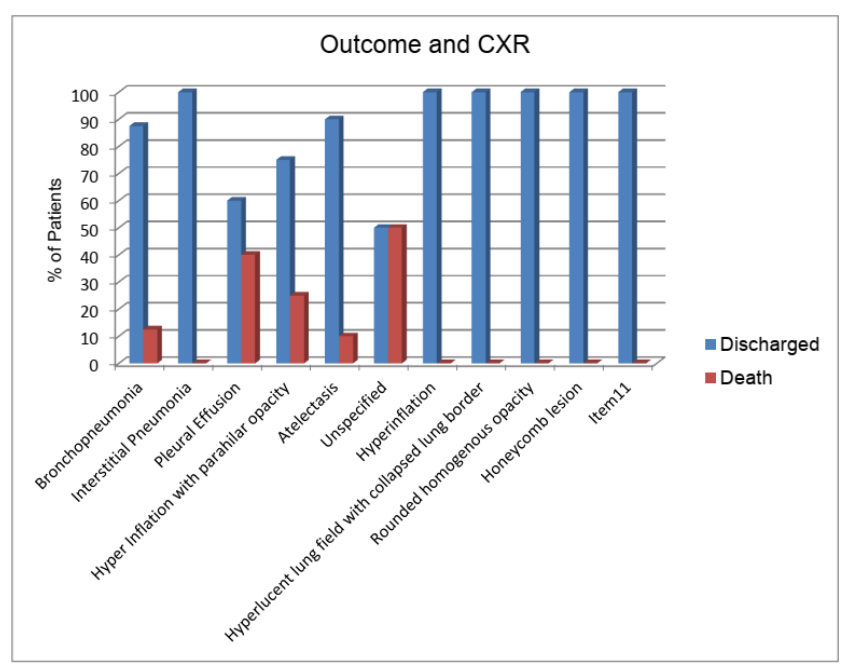

Table-24: Comparison between CXR findings and Final diagnosis

\begin{tabular}{|c|c|c|c|c|c|c|c|c|c|c|c|c|c|c|c|}
\hline & \multicolumn{11}{|c|}{ Final Dlaggnosls } & \multirow[b]{2}{*}{ Total } & \multirow[b]{2}{*}{ value } & \multirow[b]{2}{*}{ Signitcance } \\
\hline & & Astrma & Bronchlectasls & Bronchourts & Bronchopneumonla & $\begin{array}{l}\text { Forelgn } \\
\text { boty } \\
\text { Impaction }\end{array}$ & $\begin{array}{l}\text { Imarestivas } \\
\text { pnevi } \\
\text { monta }\end{array}$ & $\mathrm{m}_{\mathrm{TB}}^{\mathrm{mary}}$ & $\begin{array}{l}\text { Pleura } \\
\text { etnusion }\end{array}$ & Pneumonia & Pneumothorax & $\begin{array}{c}\text { Space } \\
\text { ocoupying } \\
\text { lesilon }\end{array}$ & & & \\
\hline \multirow{10}{*}{ CXR } & Consolldaton & $0(0)$ & $0(0)$ & $0(0)$ & $0(0)$ & $0(0)$ & 000 & $0(0)$ & 000 & $72(100)$ & $0(0)$ & 0,0 & $72(100)$ & \multirow{10}{*}{$=0.001$} & \multirow{10}{*}{ Signitcamt } \\
\hline & Eronchopneumonla & $o(0)$ & $O(0)$ & $O(0)$ & $\begin{array}{l}24 \\
1007\end{array}$ & $o(0)$ & $O(0)$ & $O(0)$ & $o(0)$ & $0(0)$ & $O(0)$ & $o(0)$ & $24(100)$ & & \\
\hline & Imlerst1al Pneumonia & $o(0)$ & $O(0)$ & $a(0)$ & $O(0)$ & $O(0)$ & $\begin{array}{l}15 \\
(100)\end{array}$ & $\alpha(0)$ & $q(0)$ & $O(0)$ & $o(0)$ & $o(0)$ & $15(100)$ & & \\
\hline & Pleural Enusion & $O(0)$ & $O(0)$ & $a(0)$ & $a(0)$ & $O(0)$ & $O(0)$ & $o(0)$ & $\begin{array}{c}12 \\
100)\end{array}$ & $O(0)$ & $o(0)$ & $o(0)$ & $12(100)$ & & \\
\hline & $\begin{array}{l}\text { Hyper Intation with parahlilar } \\
\text { opactity and increased } \\
\text { bronchovascul ar markings }\end{array}$ & $O(0)$ & $O(0)$ & $\begin{array}{l}900 \\
(100)\end{array}$ & $a(0)$ & $o(0)$ & $o(0)$ & $\alpha(0)$ & $a(0)$ & $0(0)$ & $o(0)$ & $o(0)$ & $90(100)$ & & \\
\hline & 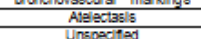 & 0,0 & $\frac{0,0)}{0,0}$ & 0,010 & $\frac{0(0)}{000}$ & 0,00 & $\frac{0,0)}{000}$ & $0(0)$ & $0,0)$ & $6(100)$ & 0,0 & 0,01 & $\frac{6(100)}{5100}$ & & \\
\hline & Hyperintaton & $\frac{45}{485}$ & $o(0)$ & $a(0)$ & $O(0)$ & $\frac{10}{6}$ & $O(0)$ & $0(0)$ & $0(0)$ & $0(0)$ & $O(0)$ & $0(0)$ & $51(100)$ & & \\
\hline & $\begin{array}{l}\text { Hyperiucent lung tald with } \\
\text { coliasesd lung pordes }\end{array}$ & $O(0)$ & $Q(0)$ & $a(0)$ & $O(0)$ & $\alpha(0)$ & $o(0)$ & $a(0)$ & $a(0)$ & $o(0)$ & $12(100)$ & $q(0)$ & $12(100)$ & & \\
\hline & Rounded hampogenous & $o(0)$ & $a(0)$ & $a(0)$ & $O(0)$ & $a(0)$ & $O(0)$ & $0(0)$ & $a(0)$ & $o(0)$ & $a(0)$ & $6(100)$ & $6(100)$ & & \\
\hline & Hongy,como lasion & 00 & $6(100)$ & $0(0)$ & 00 & $0(0)$ & 00 & $0(0)$ & 00 & $0(0)$ & $0(0)$ & 0,0 & $6(100)$ & & \\
\hline \multicolumn{2}{|r|}{ Total } & $45(15)$ & $6(2)$ & 90 & $24(8)$ & 6 6(2) & $15(5)$ & 6 6(2) & $12(4)$ & $78(26)$ & $12(4)$ & 6 6/2) & $300(100)$ & & \\
\hline
\end{tabular}




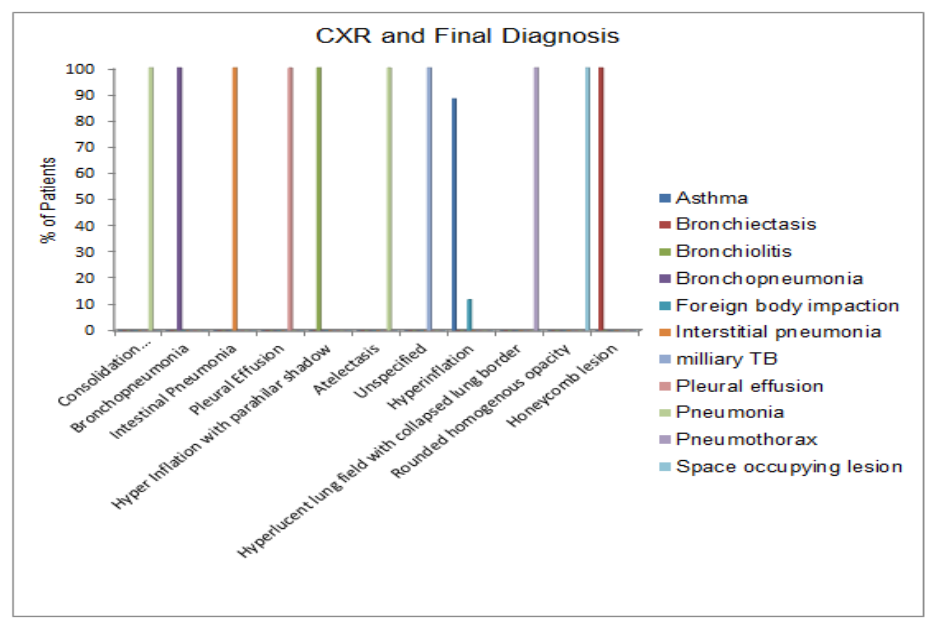

\section{DISCUSSION}

This study has been done at Calcutta National Medical College and Hospital from October 2017 to September 2018 to know the role of chest $\mathrm{x}$ ray findings in diagnosing etiology of tachypnea in children less than 5 years of age.

In this present study a total of 300 patients has been enrolled and 156(56\%) were male and 144(48\%) were female. The commonest age at presentation was less than 12 months. Most of this patients presented with fever with cough followed by fast breathing and cough; then fever with fast breathing and few cases presented with grunting $\{126(42 \%), 66(22 \%), 27$ (9\%), $9(3 \%)$ respectively\}. This finding is consistent with the study done by Salwa Ahmad Al-Najjar et al. The commonest auscultator finding is predominantly wheeze and crepitation ( $30 \%$ ) which is comparable to Salwa Ahmad Al-Najjar et al. study (82\%); followed by no finding seen in $19 \%$ cases, only wheeze $18 \%$ cases, only crepitation in $10 \%$ cases, predominantly crepitation with wheeze in $9 \%$ cases, diminished Vesicular breath sound (VBS) in 9\% cases, Predominantly Bronchial breath sound (BBS) with crepitation and wheeze in $3 \%$ cases, diminished Vesicular breath sound with wheeze in $2 \%$ cases were present. In my study, Auscultatory chest findings were present bilaterally in $49 \%$ cases, in right lung $23 \%$ cases, in left lung $11 \%$ cases [4].

In this study of three hundred patients; 294(98\%) were having abnormal chest X-ray and this finding is comparable with Ali Salih KEM, et al. study (52.3\%), but it is greater than Salwa Ahmad Al-Najjar et al. study (42.4\%), Njeze et al. study (37\%) and Mulholland et al. study(34\%). All of the above study was done on patients who have pneumonia but my study was conducted on patients only who have Tachypnea, so we can explain the difference $[1,3,4]$.

In this study most of chest $\mathrm{x}$-ray findings were seen on bilaterally in $147(49 \%)$ cases, in right lung $69(23 \%)$ cases, in left lung 33(11\%) cases. In Chest x- ray findings of my study, commonest finding was Hyperinflation with parahilar opacity; present in $90(30 \%)$ cases, Consolidation in $72(24 \%)$ cases, Hyperinflation in 51(17\%) cases, Bronchopneumonia in $24(8 \%)$ cases, Interstitial pneumonia in $15(5 \%)$ cases, Pleural effusion in 12(4\%) cases; Atelectasis, Rounded homogenous opacity, Honeycomb lesion and Unspecified findings were seen in $6(2 \%)$ cases each.

This study is similar with Patria et al. study, which showed that Parenchymal densities were more prevalent in the right than the left lung (263 vs 179) and the most frequent radiological presentation was focally distributed parenchymal densities in 212 patients $(63.3 \%)$, whereas 123 patients $(36.7 \%)$ showed multifocal consolidations; of these 123 patients predominantly bilateral consolidation seen in 85 cases $(85 / 123,69.1 \%)$ and only five radiographs $(1.5 \%)$ showed interstitial changes. This study also consistent with Brazilian study which showed pulmonary infiltrate and consolidation in 161 cases (54\%) and 119(40\%) respectively. In this study Interstitial pneumonia was seen in 15 cases $(5 \%)$ but Salwa Ahmad Al-Najjar et al. study showed that it is as common as that of consolidation [4-6].

In CXR findings of my study; Bilateral lobe $(\mathrm{B} / \mathrm{L})$ involvement was seen in $64.3 \%$ cases, Right upper lobe(RUL) most commonly involved (11.2\% cases) than Right middle lobe(RML) and Right lower lobe(RLL); which were involved in $5.1 \%$ cases each; Left upper lobe(LUL) and Left lower lobe(LUL) were involved in $3.1 \%$ cases each. These findings are similar with Grafakou et al. study (Greece) showed that from 169 chest x-rays, consolidation was right sided 109 cases and left sided in 58 cases. The majority of children with left sided pneumonia, more commonly had the lower lobe affection (lower lobe, 45/58, 77.5\%; upper lobe, 11/58, 19.1\%;upper and lower lobe, 2/58, $3.4 \%$ ), while in right-sided pneumonia, the upper lobe was more commonly affected(upper lobe, 54/109, 49.5\%; lower lobe, 35/109, 32.1\%;middle lobe, 16/109, $14.7 \%$; and more than one lobe, 4/109, 3.6\%)[7]. 
We have seen that there is an association between chest $\mathrm{x}$-ray finding with patients who presented with $>7$ days of compliant $(p<0.001)$, patients who have previous admission with similar illness $(\mathrm{p}<0.001)$. Patients who have crepitation and diminished Vesicular breath sound on auscultation have an association with chest $\mathrm{x}$-ray findings $(\mathrm{p}<0.001)$ and patients who stayed in the hospital more than 7 days also have association with chest $\mathrm{x}$ ray finding ( $\mathrm{p}<0.001)$. This is similar with Ali Salih KEM et al. (Sudan) study which showed that chest X-ray findings of the disease has significant association with many factors e.g. hospital stay more than 4 days $(p<0.001)$, presence of severe malnutrition $(\mathrm{P}<0.001)$, presence of other diseases $(\mathrm{p}<0.01)[1]$.

The mortality rate of patients in this study is $10 \%$, which is greater than Mulholland et al. study $(2.8 \%)[3]$.

\section{SUMMARY}

- In this present study, among 300 patients, $60 \%$ are infants, $26 \%$ are between 1-2 years of age and $14 \%$ are between 2-5 years of age.

- In this present study, among 300 patients, 52\% are male and $48 \%$ are female.

- In this present study, among 300 patients, 65\% from lower, $25 \%$ from middle, $10 \%$ from upper socio-economic classes.

- In this present study, Fever with cough was present in $42 \%$ cases followed by Fast breathing with cough in $22 \%$ cases, Fever with Fast breathing in $9 \%$ cases and Grunting in 3\% cases.

- In this present study, past history of similar illness was present 3 times in $38.5 \%$ cases, twice in $28.2 \%$ cases, once in $20.5 \%$ cases, 4 times in 12.85 cases.

- In this present study; Predominantly wheeze with crepitation was present in $25 \%$ cases, no finding seen in $19 \%$ cases, only wheeze $18 \%$ cases, only crepitation in $10 \%$ cases, predominantly crepitation with wheeze in 9\% cases, diminished Vesicular breath sound (VBS) in 9\% cases, Predominantly Bronchial breath sound (BBS) with crepitation and wheeze in 3\% cases, diminished Vesicular breath sound with wheeze in $2 \%$ were present.

- In this present study, Auscultatory chest findings were present bilaterally in $49 \%$ cases, in right lung $23 \%$ cases, in left lung $11 \%$ cases.

- In Chest X-ray findings of this present study, Hyperinflation with parahilar opacity was present in $30 \%$ cases, Consolidation in $24 \%$ cases, Hyperinflation in $17 \%$ cases, Bronchopneumonia in $8 \%$ cases, Interstitial pneumonia in $5 \%$ cases, Pleural effusion in $4 \%$ cases; Atelectasis, Rounded homogenous opacity, Honeycomb lesion and Unspecified findings were seen in $2 \%$ cases each.

- In CXR findings of this present study, Bilateral lobe $(\mathrm{B} / \mathrm{L})$ involvement was seen in $64.3 \%$ cases,
Right upper lobe(RUL) involved in $11.2 \%$ cases; Right middle lobe(RML), Right lower lobe(RLL) and whole left lung involved in $5.1 \%$ cases each; Left upper lobe(LUL), Left lower lobe(LUL) and whole Right lung involved in $3.1 \%$ cases each.

- In this present study, Among 300 patients Brochiolitis was diagnosed in $30 \%$ cases, Pneumonia in $26 \%$ cases, Asthma in $15 \%$ cases, Bronchopneumonia in $8 \%$ cases; Pleural effusion and Pneumothorax in $4 \%$ cases each; Bronchiectasis, Foreign body impaction, Millary Tuberculosis(TB), Space occupying lesion were diagnosed in $2 \%$ cases each.

- In this present study $50 \%$ cases stayed in hospital for $4-7$ days, $30 \%$ cases for $>7$ days and $20 \%$ case $<4$ days.

- In this present study, $90 \%$ patients were discharged after clinical improvement and death occurred in $10 \%$ cases.

\section{CONCLUSION}

In this study we have seen that chest X-ray can give useful information about the presence of pneumonia more commonly in patients who complain of cough and tachypnea for 3 days and more. So physicians should have to select patients who need $\mathrm{x}$ rays to avoid unnecessary exposure to radiation and wastage of time and money for all patients with pneumonia.

\section{REFERENCES}

1. Ali Salih, K. E. M., Wahb, O. A., \& Ibrahim, S. A. (2012). Radiological Findings in Severe Pneumonia in Children 1-59 Months in a Children's Hospital, Khartoum, Sudan. Pediatr Therapeut, 2(117), 2161-0665.

2. Njeze, N. R., Okwor, C., \& Nzegwu, M. (2011). A Correlation Between Clinical and Chest Radiographic Diagnosis of Pneumonia in Nigerian Children. Advances in bioresearch December, 2(2): 18-21

3. Magree, H.C., Russell, F.M., Sa'aga, R., Greenwood, P., Tikoduadua, L. (2005). Chest Xray-confirmed pneumonia in children in Fiji. Bull World Health Organ, 83: 427-433

4. Al-Najjar, S. A., Al-Rabaty, A., \& Al-Hatam, I. (2013). Analysis of chest X-ray and clinical finding in children with pneumonia. Zanco Journal of Medical Sciences (Zanco J Med Sci), 17(2), 477481.

5. Patria, M. F., Longhi, B., Lelii, M., Galeone, C., Pavesi, M. A., \& Esposito, S. (2013). Association between radiological findings and severity of community-acquired pneumonia in children. Italian journal of pediatrics, 39(1), 56.

6. NK, K., ARAÚJO-NETO, C.A., \$M-RA, Cardoso., \& CM Nascimento-Carvalho. (2011). Indian Pediatrics Characteristics of Radiographically 
Diagnosed Pneumonia inUnder-5 Children in Salvador, Brazil, 48(17).

7. Grafakou, O., Moustaki, M., Tsolia, M., Kavazarakis, E., Mathioudakis, J., Fretzayas, A., \& Karpathios, T. (2004). Can chest X-ray predict pneumonia severity?. Pediatric pulmonology, 38(6), 465-469.

8. Puumalainen, T., Quiambao, B., AbucejoLadesma, E., Lupisan, S., Heiskanen-Kosma, T., Ruutu, P., ... \& ARIVAC Research Consortium. (2008). Clinical case review: a method to improve identification of true clinical and radiographic pneumonia in children meeting the World Health Organization definition for pneumonia. $B M C$ infectious diseases, 8(1), 95.

9. Guo, W., Wang, J., Sheng, M., Zhou, M., \& Fang, L. (2012). Radiological findings in 210 paediatric patients with viral pneumonia: a retrospective case study. The British journal of radiology, 85(1018), 1385-1389.

10. Falade, A. G., Tschäppeler, H., Greenwood, B. M., \& Mulholland, E. K. (1995). Use of simple clinical signs to predict pneumonia in young Gambian children: the influence of malnutrition. Bulletin of the World Health Organization, 73(3), 299.

11. Xavier-Souza, G., Vilas-Boas, A. L., Fontoura, M. S. H., Araújo-Neto, C. A., Andrade, S. C., Cardoso, M. R. A., ... \& PNEUMOPAC-Efficacy Study Group. (2013). The inter-observer variation of chest radiograph reading in acute lower respiratory tract infection among children. Pediatric pulmonology, 48(5), 464-469.

12. Yoshida, L. M., Nguyen, H. A., Watanabe, K., Le, M. N., Nguyen, A. T., Vu, H. T., ... \& Moriuch, H. (2013). Incidence of radiologically-confirmed pneumonia and Haemophilus influenzae type $b$ carriage before Haemophilus influenzae type b conjugate vaccine introduction in Central Vietnam. The Journal of pediatrics, 163(1), S38S43.

13. Javadi, M., Subhannachart, P., Levine, S., Vijitsanguan, C., Tungsagunwattana, S., Dowell, S. F., \& Olsen, S. J. (2006). Diagnosing pneumonia in rural Thailand: Digital cameras versus film digitizers for chest radiograph teleradiology. International Journal of Infectious Diseases, 10(2), 129-135.

14. Castro-Rodriguez, J. A., Mallol, J., Rodriguez, J., Auger, F., \& Andrade, R. (2008). Risk factors for $\mathrm{X}$-ray pneumonia in the first year of life and its relation to wheezing: a longitudinal study in a socioeconomic disadvantaged population. Allergologia immunopathologia, 36(1), 3-8.

15. Nacul, L. C., Kirkwood, B. R., Carneiro, A. C., Pannuti, C. S., Magalhaes, M., \& Arthur, P. (2005). Aetiology and clinical presentation of pneumonia in hospitalized and outpatient children in Northeast
Brazil and risk factors for severity. Journal of Health, Population and Nutrition, 6-15.

16. Johnson, J., \& Kline, J. A. (2010). Intraobserver and interobserver agreement of the interpretation of pediatric chest radiographs. Emergency radiology, 17(4), 285-290.

17. Neuman, M. I., Lee, E. Y., Bixby, S., Diperna, S., Hellinger, J., Markowitz, R., ... \& Shah, S. S. (2012). Variability in the interpretation of chest radiographs for the diagnosis of pneumonia in children. Journal of hospital medicine, 7(4), 294298.

18. DeRenzi, B., Lesh, N., Parikh, T., Sims, C. Maokla, W., Chemba, M., ... \& Borriello, G. (2008, April). E-IMCI: Improving pediatric health care in low-income countries. In Proceedings of the SIGCHI conference on human factors in computing systems (pp. 753-762). ACM.

19. Pauls, S., Krüger, S., Richter, K., Muche, R., Marre, R., Welte, T., ... \& Aschoff, A. J. (2007). Interobserver agreement in the assessment of pulmonary infiltrates on chest radiography in community-acquired pneumonia. RoFo: Fortschritte auf dem Gebiete der Rontgenstrahlen und der Nuklearmedizin, 179(11), 1152-1158.

20. Madhi, S. A., \& Klugman, K. P. (2007). World Health Organisation definition of "radiologicallyconfirmed pneumonia" may under-estimate the true public health value of conjugate pneumococcal vaccines. Vaccine, 25(13), 2413-2419.

21. Cardinale, F., Cappiello, A. R., Mastrototaro, M. F., Pignatelli, M., \& Esposito, S. (2013). Community-acquired pneumonia in children. Early human development, 89, S49-S52.

22. Swingler, G. H. (2008). Chest radiography for children with pneumonia: a century of folly?. Indian pediatrics, 45(11), 889.

23. World Health Organization. Programme for the Control of Acute Respiratory Infections. (1990). Report of a meeting of the Radiology Working Group (Geneva, 27-28 October 1989). Geneva: World Health Organization, 1-22. (WHO/ARI/90.13).

24. Lynch, T., Platt, R., Gouin, S., Larson, C., \& Patenaude, Y. (2004). Can we predict which children with clinically suspected pneumonia will have the presence of focal infiltrates on chest radiographs?. Pediatrics, 113(3), e186-e189.

25. Cherian, T., Mulholland, E. K., Carlin, J. B., Ostensen, H., Amin, R., Campo, M. D., ... \& O'Brien, K. L. (2005). Standardized interpretation of paediatric chest radiographs for the diagnosis of pneumonia in epidemiological studies. Bulletin of the World Health Organization, 83, 353-359.

26. Cherian, T., Mulholland, E. K., Carlin, J. B., Ostensen, H., Amin, R., Campo, M. D., ... \& O'Brien, K. L. (2005). Standardized interpretation of paediatric chest radiographs for the diagnosis of 
pneumonia in epidemiological studies. Bulletin of the World Health Organization, 83, 353-359.

27. Kumar, N., Singh, N., Locham, K. K., Garg, R., \& Sarwal, D. (2002). Clinical evaluation of acute respiratory distress and chest wheezing in infants. Indian pediatrics, 39(5), 478-483.

28. Sehgal, V., Sethi, G. R., Sachdev, H. P. S., \& Satyanarayana, L. (1997). Predictors of mortality in subjects hospitalized with acute lower respiratory tract infections. Indian pediatrics, 34(3), 213-9.

29. Reddaiah,V. P., Kapoor, S. K. (1995). Acute respiratory infections in fewer than five: Experience at comprehensive rural health services project hospital Ballabgarh. Indian J Community Med, 20: 1-4.

30. John, S. Bradley. (1995). The Management of Community-Acquired Pneumonia in Infants and Children Older than 3 Months of Age: Clinical Practice Guidelines by the Pediatric Infectious Diseases Society and the Infectious Diseases Society of America (IDSA); Downloaded from cid.oxfordjournals.org at IDSA.

31. Kin, K.N., Aurajo-Neto, C.A., \& NasimentoCarvalho, C.M. (2009). Severity of childhood community acquired pneumonia and chest radiograph findings. Pediatr Pulmonol, 44:249-2

32. Hazir, T., Nisar, Y.B., Qazi, S.A. (2006). Chest radiography in children aged 2-59 months diagnosed with non-severe pneumonia as defined by World Health Organization: descriptive multicentre study in Pakistan. BMJ. 333:629.

33. O'Grady, K.F., Torzillo, P.J., Ruben, A.R. (2012). Identification of radiological alveolar pneumonia in children with high rates of hospitalized respiratory infections: comparison of WHO-defined and paediatric pulmonologist diagnosis in the clinical context.Pediatr Pulmonol, 47: 386-92.

34. Rasa Izadnegahdar, Adam, L.C., Keith, P. K., Shamim, A.Q. (2013). Childhood pneumonia in developing countries Lancet Respir Med. 1: 57484.

35. Shimol, B.S., Dagan, R., Givon-Lavi, N. (2012). Evaluation of the World Health Organization criteria for chest radiographs for pneumonia diagnosis in children. Eur J Pediatr, 171: 369-74.

36. Cherian, T., Mulholland, E.K., Carlin, J.B. (2005). Standardized interpretation of paediatric chest radiographs for the diagnosis of pneumonia in epidemiological studies. Bull World Health Organ, 83:353-9.

37. Novack,V., Avnon, L.S., Smolyakov., A. (2006). Disagreement in the interpretation of chest radiographs among specialists and clinical outcomes of patients hospitalized with suspected pneumonia. Eur J Intern Med, 17:43-7.

38. Swingler, G.H., Hussey, G.D., Zwarenstein, M. (1998). Randomised controlled trial of clinical outcome after chest radiograph in ambulatory acute lower-respiratory infection in children. Lancet, 351:404-8.

39. Swingler, G.H., Zwarenstein, M.(2008). Chest radiograph in acute respiratory infections. Cochrane Database Syst Rev; 23:CD001268.

40. Palafox, M., Guiscafre, H., Reyes, H.(2000). Diagnostic value of tachypnoea in pneumonia defined radiologically. Arch Dis Child, 82:41-5.

41. World Health Organization. (1995). The management of acute respiratory infections in children In: Practical guidelines for outpatient care. Geneva: WHO.

42. Pneumonia progress report. (2012). International Vaccine Access Center at the Johns Hopkins Bloomberg School of Public Health. November; www.jhsph.edu/ivac.

43. Committing to Child Survival: A Promise Renewed. Progress Report UNICEF; 2012. WHO publication.

44. Statistical snapshot child mortality. UNICEF; 2013. WHO publication.

45. British thoracic society Guidelines for the management of community acquired pneumonia in children: update 2011. Thorax 2011; 66:ii1-ii23.

46. Pneumonia: The forgotten killer of children. The United Nations Children's Fund (UNICEF)/World Health Organization (WHO), 2006.

47. Deb, S.K. (1998). Acute respiratory disease survey in Tripura in case of children below five years of age. J Indian Med Assoc, 96:111-6

48. Dharmage, S.C., Rajapaksa, L.C., Fernando, D.N. (1996). Risk factors of acute lower respiratory tract infections in children under five years of age. Southeast Asian Journal of Tropical Medicine and Public Health, 27(1):107-10.

49. Chhabra, P. (1993). Magnitude of acute respiratory infections in underfives. Indian Paediatrics. 1993; 30:1315-18.

50. Nelson Textbook Of Paediatrics First South Asia Edition

51. Selvaraj, K., Chinnakali, P., Majumdar, A., Krishnan, I.S. (2014). Acute respiratory infections among under-5 children in India: A situational analysis. J Nat Sci Biol Med, 5:15-20. 